\title{
Commentary on "A Case of Acute Cardiomyopathy and Pericarditis Associated with Methylphenidate"; Cardiovasc Toxicol, DOI 10.1007/s12012-009-9033-7
}

\author{
Ahmad Ghanizadeh
}

Published online: 5 May 2009

(C) Humana Press 2009

Thanks for the interesting case report by Dadfarmay et al. [1] entitled: "a case of acute cardiomyopathy and pericarditis associated with methylphenidate." I appreciate the authors for providing more opportunities for discussion and reminding possible adverse effects of methylphenidate.

The authors reported a 17-year-old boy with ADHD who suffered from symptoms such as chest pain, elevated cardiac biomarkers, and acute left ventricular dysfunction after taking a single dose of methylphenidate. He developed ST elevation in EKG that was normalized with $36 \mathrm{~h}$. Then, the authors mentioned association of cardiomyopathy and pericarditis with methylphenidate. This association was supported by the reports of previous studies [2, 3].

The association needs to be more discussed because of the following issues.

First, the patient's urinary screening test was positive for marijuana. The possible association of the patient's findings and marijuana should be reminded $[4,5]$. Moreover, is it possible that methylphenidate and marijuana have additive effect and caused the symptoms?

Second, there were two studies mentioned in support of cardiomyopathy and association of methylphenidate. The reference of Tollofsrud [3] was not in English and I could not study it. The second reference, the Nymark et al. [2] reported a patient with body mass index of 40 who has taken quetiapine $900 \mathrm{mg} /$ day for 17 months and methylphenidate was added. However, there is another report for possible association of cardiomyopathy and methamphetamine use in young patients [6]. So, there is an argument if the cardiomyopathy is just related to methylphenidate.

\section{References}

1. Dadfarmay, S., \& Dixon, J. (2009). A case of acute cardiomyopathy and pericarditis associated with methylphenidate. Cardiovascular Toxicology. doi:10.1007/s12012-009-9033-7.

2. Nymark, T. B., Hovland, A., Bjornstad, H., \& Nielsen, E. W. (2008). A young man with acute dilated cardiomyopathy associated with methylphenidate. Vascular Health and Risk Management, 4, 477-479.

3. Tollofsrud, C., \& Hoel, T. (2006). A young man with acute dilated cardiomyopathy. Tidsskrift for den Norske Laegeforening, 126, 1338-1339.

4. Ting, J. Y. (2007). Reversible cardiomyopathy associated with acute inhaled marijuana use in a young adult. Clinical Toxicology (Philadelphia), 45(4), 432-434.

5. Leontiadis, E., Morshuis, M., Arusoglu, L., Cobaugh, D., Koerfer, R., \& El-Banayosy, A. (2008). Thoratec left ventricular assist device removal after toxic myocarditis. Annals of Thoracic Surgery, 86(6), 1982-1985.

6. Yeo, K. K., Wijetunga, M., Ito, H., Efird, J. T., Tay, K., Seto, T. B., et al. (2007). The association of methamphetamine use and cardiomyopathy in young patients. American Journal of Medicine, 120(2), 165-171.
A. Ghanizadeh $(\bowtie)$

Department of Psychiatry, Research Center for Psychiatry

and Behavioral Sciences, Hafez Hospital, Shiraz University

of Medical Sciences, Shiraz, Iran

e-mail: ghanizad@sina.tums.ac.ir; ghanizadeha@hotmail.com 